\title{
HUBUNGAN ANTARA SELF EFFICACY DENGAN QUALITY OF LIFE PADA PASIEN DIABETES MELLITUS TIPE 2 DI WILAYAH KERJA PUSKESMAS KEBONSARI SURABAYA
}

\author{
Nety Mawarda Hatmanti \\ Fakultas Keperawatan dan Kebidanan \\ Universitas Nahdlatul Ulama Surabaya, Jln. Smea 57 Surabaya \\ E-mail: nety.mawarda@unusa.ac.id
}

\begin{abstract}
Diabetes Mellitus (DM) is a group of metabolic diseases characterized by hyperglycemia resulting from defects in insulin secretion, insulin action, or both. Diabetes Mellitus type 2 is a significant problem in the global health. This research was purposed to find out the correlation between self-efficacy and quality of life of the patients with Diabetes Mellitus type 2. The design of this research was cross sectional, in which 16 patients visiting the polyclinic of Puskesmas Gayungan Surabaya were chosen as the samples. The result of research using Spearman rho test showed that there was a significant correlation between self-efficacy and quality of life proved by the $p$ value $=0.016<0.05$. The conclusion of this research found a positive intermediate correlation between selfefficacy and quality of life so that nurses are required to ask the family to increase the patients' self-efficacy.
\end{abstract}

Key words: Diabetes Mellitus type 2, self-efficacy, quality of life.

Abstrak : Diabetes mellitus (DM) merupakan penyakit metabolik dengan karakteristik hiperglikemia karena kelainan sekresi insulin, kerja insulin atau keduanya. Diabetes mellitus tipe merupakan masalah yang signifikan dalam kesehatan global. Penelitian ini bertujuan untuk mengetahui hubungan antara self efficacy dengan quality of life pada pasien dengan Diabetes mellitus tipe 2. Desain dalam penelitian ini menggunakan cross sectional design dengan jumlah sampel sebanyak 16 pasien yang kontrol di Poli Umum Puskesmas Kebonsari Surabaya. Hasil penelitian dengan menggunakan uji Spearman rho menunjukkan bahwa terdapat hubungan yang bermakna antara self efficacy dan quality of life yang ditunjukkan dengan nilai p. $0,016<0,05$. Kesimpulan penelitian ini adalah ada hubungan ke arah korelasi positif dengan kekuatan korelasi yang sedang antara self efficacy dengan quality of life, sehingga perawat perlu berusaha untuk mengajak keluarga dalam meningkatkan self efficacy pasien dengan Diabetes mellitus tipe 2.

Kata kunci : Diabetes mellitus tipe 2, self efficacy, quality of life

\section{PENDAHULUAN}

Diabetes mellitus (DM) merupakan penyakit metabolik dengan karakteristik hiperglikemia karena kelainan sekresi insulin, kerja insulin atau keduanya. Walaupun tampilan klinis DM biasanya ringan dan tanpa gejala, perjalanan penyakit dapat berkembang kronis dan progresif serta menyebabkan komplikasi akut dan kronis. Komplikasi kronis dapat mengenai mikrovaskular seperti retinopati dan nefropati diabetik serta makrovaskular seperti penyakit kardiovaskular, arteri perifer dan serebrovaskular. (Perkeni, 2011) 
Diabetes mellitus merupakan masalah yang signifikan dalam kesehatan global. Sampai saat ini Diabetes mellitus adalah penyakit yang belum bisa disembuhkan. Pembatasan makanan, pengobatan termasuk injeksi insulin pada penderita Diabetes mellitus berhubungan dengan angka kejadian sakit yang nantinya juga akan mempengaruhi QoL (Quality of Life) pada penderita Diabetes mellitus (WHO, 2012). WHO mendefinisikan kesehatan tidak hanya terbatas pada tidak adanya penyakit dan kecacatan saja, melainkan juga menyangkut pada kesehatan fisik, psikologis dan kesejahteraan sosial. Pengobatan Diabetes mellitus tujuannya selain untuk mengatasi kejadian glikemia, akan tetapi juga untuk meningkatkan kualitas hidupnya (QoL) dalam menjalani penyakitnya (Choi \& Kim, 2011).

Diabetes mellitus merupakan kumpulan gejala yang timbul pada seseorang akibat tubuh mengalami gangguan dalam mengontrol kadar gula darah. Gangguan tersebut dapat disebabkan oleh sekresi hormon insulin yang tidak adekuat atau fungsi insulin terganggu (resistensi insulin) atau justru gabungan dari keduanya. Dalam Diabetes Atlas 2000 (International Diabetes Federation) tercantum perkiraan penduduk Indonesia di atas 20 tahun sebesar 125 juta dan dengan asumsi prevalensi Diabetes mellitus sebesar $4,6 \%$ diperkirakan pada tahun 2000 berjumlah 5,6 juta. Berdasarkan pola pertambahan penduduk seperti saat ini, diperkirakan pada tahun 2020 nanti akan ada sejumlah 178 juta penduduk berusia di atas 20 tahun dan dengan asumsi prevalensi Diabetes mellitus sebesar 4,6\% akan didapatkan 8,2 juta pasien diabetes (Soegondo, 2011).

WHO (2012) menyatakan bahwa sebanyak 346 juta orang di dunia menderita Diabetes mellitus. Pada tahun 2004 diperkirakan sebanyak 3,4 juta orang meninggal dikarenakan kadar gula darah yang tinggi dan $80 \%$ kematian penderita Diabetes mellitus dialami oleh penduduk di negara dengan pendapatan ekonominya menengah ke bawah. Pada tahun 2030 diperkirakan penyakit Diabetes mellitus akan menjadi penyebab kematian nomer tujuh di dunia. WHO (2012) memprediksi jumlah kematian dikarenakan penyakit Diabetes mellitus akan meningkat dua kali lipat antara tahun 2005 sampai 2030. Pada orang dewasa yang terkena diabetes, resiko kematian menjadi dua kali lipat dibandingkan dengan orang dewasa tanpa Diabetes mellitus (PERKENI, 2011).

WHO (2012) menyebutkan bahwa di Indonesia penyakit Diabetes mellitus terus meningkat sampai dengan angka 8,4 juta jiwa, yang artinya 1 dari 40 penduduk menderita Diabetes mellitus dan angka ini akan diprediksi terus meningkat melebihi 21,3 juta jiwa pada tahun 2030 mendatang dan komposisinya lebih banyak pada usia muda dan usia yang produktif. Senada dengan WHO (World Health Organization), International Diabetes Federation (IDF) pada tahun 2009, memprediksi kenaikan jumlah penyandang Diabetes mellitus dari 7 juta pada tahun 2009 menjadi 12 juta pada tahun 2030. Meskipun terdapat perbedaan angka prevalensi, laporan keduanya menunjukkan adanya peningkatan jumlah penyandang Diabetes mellitus sebanyak 2-3 lipat pada tahun 2030 (Anggina, 2010).

Di Indonesia prevalensi Diabetes mellitus tipe 1 secara pasti belum diketahui, tetapi diakui memang sangat jarang, karena mungkin disebabkan oleh Indonesia terletak di khatulistiwa (semakin jauh dari garis khatulistiwa, semakin banyak insiden Diabetes mellitus tipe 1) atau barangkali faktor genetik memang mendukung, juga bisa disebabkan karena diagnosis Diebetes mellitus tipe 1 yang terlambat sehingga pasien sudah meninggal akibat komplikasi sebelum didiagnosis. Lain halnya dengan Diabetes mellitus tipe 2 yang jumlahnya lebih dari 
90\% dari semua populasi Diabetes mellitus di Indonesia (Soegondo, 2011). Oleh karena alasan inilah, peneliti memfokuskan pada penderita Diabetes mellitus tipe 2 yang jumlahnya terus meningkat.

Dari data yang didapatkan oleh peneliti dari Dinas Kesehatan Kota Surabaya, didapatkan bahwa pada tahun 2009 jumlah penderita Diabetes mellitus di kota Surabaya sebanyak 16.365 penduduk, dan menurun pada tahun 2010 sebanyak 15.509 penduduk. Di puskesmas Kebonsari didapatkan bahwa jumlah penderita Diabetes mellitus sebanyak 220 orang pada tahun 2009, dan meningkat menjadi 315 orang pada tahun 2010. Data yang didapatkan di puskesmas Kebonsari, jumlah penderita pada bulan Pebruari 2012 sebanyak 45 penderita perempuan dan 28 penderita laki laki (diantaranya 9 penderita baru terdeteksi), sedangkan pada bulan Maret 2012 didapatkan data sebanyak 50 penderita perempuan dan 27 penderita laki-laki (diantaranya 7 penderita baru terdeteksi). Di puskesmas Kebonsari sendiri telah diadakan program untuk perkumpulan para penderita Diabetes mellitus setiap bulan sekali pada minggu kedua dan semua penderita diundang dan difasilitasi dari pihak puskesmas. Akan tetapi pada kenyataannya yang hadir hanya sedikit saja sekitar 30 orang setiap acara. Rata-rata alasan dari para penderita diantaranya mengurus cucu di rumah, tidak ada yang mengantar dan bekerja. Di puskesmas Kebonsari juga telah diadakan kunjungan ke rumah penderita Diabetes mellitus yang baru dan sudah terjadwal untuk diberikan penyuluhan dengan rentang waktu yang lama dikarenakan keterbatasan tenaga kesehatan di Puskesmas.

Diabetes mellitus merupakan penyakit menahun yang akan diderita seumur hidup dan tidak bisa disembuhkan akan tetapi bisa dikontrol agar tidak terjadi komplikasi. Dalam pengelolaannya, selain dokter, perawat, ahli gizi dan tenaga kesehatan lain, peran pasien dan keluarga menjadi sangat penting. Edukasi kepada pasien dan keluarganya bertujuan dengan memberikan pemahaman mengenai perjalanan penyakit, pencegahan, penyulit dan penatalaksanaan Diabetes mellitus akan sangat membantu meningkatkan keikutsertaan keluarga dalam usaha memperbaiki hasil pengelolaan. Banyak sekali intervensi yang telah dilakukan untuk pengelolaan penderita Diabetes mellitus tipe 2, diantaranya program DSME (Diabetes Self Management Education) yang mampu meningkatkan self efficacy dan self behaviour (Rondhianto, 2011), peer support yang mampu meningkatkan self care attitudes (Rochmi, 2009).

Berdasarkan teori sosial kognitif yang dikemukakan oleh Bandura (1997) menyatakan bahwa motivasi dan tindakan manusia diatur secara ekstensif oleh pemikirannya. Faktor utama yang mempengaruhi perilaku seseorang adalah self efficacy, yaitu keyakinan seseorang tentang kemampuannya sendiri untuk melakukan suatu tindakan yang diinginkan sehingga bisa mencapai hasil yang diinginkan. (Luszczynska, 2005). Model self efficacy menawarkan suatu kerangka kerja yang berguna untuk mengetahui dan melihat kepatuhan pasien dalam perilaku self care (Shortridge-Bagget, 2001). Ada 2 (dua) komponen kognitif dalam teori ini antara lain efficacy expectations (rasa percaya diri seseorang untuk mampu dalam melaksanakan suatu tugas) dan outcome expectations (suatu kepercayaan bahwa perilaku yang diterapkan akan sesuai dengan keinginan atau tujuan awal); dan keduanya mempengaruhi keseimbangan dari perilaku seseorang (Bandura, 1997).

Self efficacy memberikan landasan untuk keefektifan self management pada Diabetes mellitus karena berfokus pada perubahan perilaku 
penderita (Shortridge-Baggett, 2001). Beberapa penelitian telah menunjukkan hubungan yang baik antara self efficacy dengan perilaku self care pada pasien diabetes, dan self efficacy merupakan hal berguna untuk mengetahui perilaku self care pada pasien Diabetes mellitus (Wu, 2007). Penelitian yang dilakukan sebelumnya oleh Nyunt (2010) di Bangkok menyimpulkan bahwa penderita Diabetes mellitus yang memiliki level self efficacy yang tinggi dan self care yang bagus mempunyai kemampuan yang baik untuk mengontrol glikemia. Hal tersebut menunjukkan bahwa dukungan terhadap self efficacy dan self care pada penderita Diabetes mellitus sangat baik untuk penatalaksanaan dan peningkatan pengetahuan pada penderita. Untuk meningkatkan kemampuan mengontrol keadaan glikemia pada penderita Diabetes mellitus sangat penting untuk meningkatkan self efficacy pada penderita, dengan cara pemberdayaan tenaga kesehatan yang profesional dan keluarga panderita.

Health-related Quality of Life (HRQoL) adalah hasil yang dilaporkan oleh pasien, biasanya ditunjukkan dengan pengukuran menggunakan instrument yang telah dibakukan dan divalidasi seperti kuisioner atau wawancara semi terstruktur. HRQoL mencakup tentang keadaan fisik, fungsinya, sosial dan keadaan emosional dari seseorang (Borrot $\&$ Bush 2008). Beberapa instrument telah tersedia untuk pengukuran HRQoL pada pasien Diabetes mellitus, termasuk instrument secara umum dan spesifik. Instrument secara umum dibuat untuk meneliti tentang aspek yang dianggap penting dalam kesehatan pasien dan dibandingkan dengan mengikuti HRQoL pada pasien di group lain. Lain halnya dengan instrument spesifik, pada instrument ini mencoba untuk mengukur dampak spesifik dari pasien dengan Diabetes mellitus yaitu tentang fungsi tubuh dan kualitas hidup pasien (Quality of Life) dan bisa lebih sensitif untuk perbedaan klinis yang dianggap penting. Dari hasil review menunjukkan bahwa dimensi instrument diabetes yang spesifik telah dicakup oleh instrument yang berbeda, tetapi pada umumnya didalamnya terdapat fungsi fisiologis, fungsi psikologis, pemenuhan kebutuhan sosial, kontrol Diabetes mellitus dan kepuasan terapi. Dalam hal instrument, peneliti menggunakan instrument yang dikeluarkan oleh World Health Organization (WHO) untuk pengukuran Quality of Life karena telah terstandar.

Dari paparan di atas, mengingat Diabetes mellitus merupakan penyakit menahun yang akan diderita seumur hidup, dalam pengelolaan penyakit tersebut selain dokter, perawat, ahli gizi dan tenaga kesehatan lain, maka peran pasien dan keluarga menjadi sangat penting sehingga diharapkan memiliki peran dalam meningkatkan self efficacy pada pasien untuk tetap mempertahankan keinginan dalam memperbaiki kondisi selama hidupnya dan juga mempertahankan kualitas hidup yang berhubungan dengan kesehatannya saat ini (Health-related Quality of Life). Penelitian akan diadakan di Puskesmas Kebonsari dikarenakan jumlah penderita di wilayah kerja puskesmas tersebut semakin lama semakin meningkat. Dari segi kemudahan, di Puskesmas Kebonsari sudah terdapat perkumpulan penderita Diabetes mellitus sehingga penelitian mudah dilaksanakan.

\section{HASIL \& PEMBAHASAN}

\section{a. Hasil}

Data khusus berisi tentang self efficacy, quality of life dan hubungan antara self efficacy dengan quality of life pada lansia dengan Diabetes mellitus tipe 2 di Puskesmas Gayungan Surabaya

1) Self Efficacy

Tabel 1 Distribusi nilai self efficacy 


\begin{tabular}{clccc}
\hline No. & Variabel & Mean & SD & $\begin{array}{c}\text { Min- } \\
\text { Maks }\end{array}$ \\
\hline 1. & Self & 37,31 & 10,018 & $\begin{array}{c}17- \\
\text { efficacy }\end{array}$ \\
\end{tabular}

Sumber: Data Primer, Juni 2013

Berdasarkan tabel 1 dapat diketahui bahwa rata-rata nilai self efficacy responden adalah 37,31 .

2) Quality of Life

Tabel 2 Distribusi nilai quality of life

\begin{tabular}{|c|c|c|c|c|c|c|}
\hline $\begin{array}{c}\text { N } \\
\text { o. }\end{array}$ & Variabel & Mean & Median & Modus & SD & \\
\hline 1. & $\begin{array}{c}\text { Quality of } \\
\text { life }\end{array}$ & 60,31 & 62,50 & 64 & 6,64 & \\
\hline
\end{tabular}

Sumber: Data Primer, Juni 2013

Berdasarkan tabel 2 dapat diketahui bahwa rata-rata nilai quality of life responden adalah 60,31 .

3) Hubungan antara self efficacy dengan quality of life

Berdasarkan hasil uji Spearman rho didapatkan nilai $\mathrm{p} 0,016<0,05(\alpha)$, artinya terdapat hubungan yang bermakna antara self efficacy dan quality of life. Sedangkan nilai $r_{\mathrm{s}}$ hitung 0,591 menunjukkan bahwa arah korelasi positif dengan kekuatan korelasi yang sedang (Sugiyono, 2000).

\section{b. Pembahasan}

Pada responden bisa dilihat bahwa variasi untuk nilai self efficacy banyak terdapat pada jenis kelamin laki-laki. Jenjang pendidikan pada responden yang nilai self efficacy nya tinggi didominasi oleh responden yang lulusan SLTA, penghasilan juga ikut mempengaruhi nilai self efficacy terutama pada responden lakilaki, sedangkan pada responden perempuan tidak terlihat bahwa penghasilan mendominasi nilai self efficacy.

Menurut penelitian yang dilakukan oleh Walker, 2007 (cit. Rondhianto, 2010) waktu penerimaan seseorang terhadap penyakit yang dideritanya juga akan mempengaruhi self efficacy seseorang. Selain itu tingkat penghasilan yang lebih tinggi juga ikut berperan dalam self efficacy seseorang dikarenakan mereka akan mempunyai sumber daya ekonomi yang lebih untuk mendapatkan akses pelayanan kesehatan yang memadai dan sesuai. Berdasarkan penelitian dari Mystakidou, 2010 (cit. Rodhianto, 2010) menyebutkan bahwa laki-laki memiliki self efficacy lebih tinggi dari pada Min-perempuan.

Maks Menurut Bandura (1997), self efficacy terdapat 3 dimensi, diantaranya (1) magnitude (tingkat) dimana tingkat kesulitan seseorang juga akan berpengaruh pada pemilihan perilaku yang akan dipilih berdasarkan harapan akan keberhasilannya, (2) generality (keadaan umum) dimana berbagai pengalaman pribadi yang dibandingkan dengan pengalaman orang lain juga mampu meningkatkan self efficacy seseorang, (3) strength (kekuatan) dimana dimensi ini merupakan kekuatan keyakinan yang dimiliki oleh seseorang akan kemampuan yang dimilikinya. Jika harapan seseorang lemah bisa jadi disebabkan oleh karena kegagalan, tetapi seseorang yang punya harapan yang kuat maka walaupun gagal, dia akan tetap mau berusaha. Menurut Bandura (1977), self efficacy seseorang itu dipengaruhi oleh beberapa faktor yang bisa menyebabkan self efficacy itu meningkat, menurun, diperoleh ataupun diubah, faktor yang bisa mempengaruhi diantaranya pengalaman masa lalu seseorang, (2) pembelajaran dari pengalaman orang lain, (3) persuasi verbal dari orang lain, dan (4) kondisi emosional seseorang. Menurut Bandura (1994) suatu perubahan tingkah laku hanya akan terjadi apabila ada perubahan self efficacy pada individu yang bersangkutan. Perubahan self efficacy perlu dilakukan untuk memperbaiki kesulitan dan adaptasi tingkah laku individu yang memiliki masalah perilaku. 
Pada nilai quality of life, responden perempuan lebih tinggi daripada responden laki-laki. Dari tingginya nilai quality of life, sebagian besar mempunyai pendidikan SLTA, sedangkan pekerjaannya adalah pensiunan. Untuk lama menderita Diabetes mellitus, kebanyak responden berada pada rentang 1-10 tahun. Hal ini juga akan berpengaruh pada quality of life seseorang, dimana pengetahuan, perilaku diet dan latihan fisik dapat mempengaruhi quality of life seseorang (Rose, 2002). Pada responden yang pensiunan, maka kegiatan yang dilakukan adalah kebanyak aktifitas fisik untuk mengisi kesibukannya sehari-hari.

Menurut Polonsky (2000), alasan seseorang yang terkena Diabetes mellitus harus mempertahankan quality of life ada 2, diantaranya (1) Diabetes mellitus adalah penyakit kronik yang tidak bisa diobati secara tuntas, sehingga jika hal itu tidak terkontrol dengan baik, maka akan menjadi lebih buruk, (2) quality of life yang rendah pada seseorang akan dapat memperburuk gangguan metabolik baik secara langsung maupun tidak langsung. Menurut WHO, 2003 domain dalam quality of life ada 4 domain, diantaranya (1) aspek fisik, (2) aspek psikologis yang dalam hal ini salah satunya adalah perasaan positif dalam melakukan sesuatu yang mendukung untuk kesehatannya, (3) hubungan sosial, dimana dalam hal ini adanya dukungan dari teman, keluarga dan pemberi pelayanan kesehatan, lingkungan.

Berdasarkan hasil uji Spearman rho didapatkan hasil bahwa terdapat hubungan dengan kekuatan korelasi sedang yang bermakna antara self efficacy dan quality of life.

Menurut Bandura (1994) perubahan tingkah laku hanya akan terjadi apabila adanya perubahan self efficacy pada individu yang bersangkutan. Self efficacy akan mempengaruhi empat proses dalam diri manusia, yaitu proses kognitif, motivasional, afektif dan seleksi. Dari segi proses kognitif, self efficacy akan berpengaruh terhadap bagaimana pola pikir yang dimiliki seseorang dapat mendorong atau menghambat perilaku seseorang. Sebagian besar individu akan berpikir dahulu sebelum melakukan suatu tindakan. Seseorang dengan self efficacy yang tinggi akan dapat mendorong seseorang untuk melakukan tindakan untuk mencapai kesuksesan sehingga bisa memperkuat self efficacy seseorang. Dari proses motivasional, seseorang dapat termotivasi oleh harapan yang diinginkannya. Self efficacy merupakan salah satu hal terpenting dalam mempengaruhi diri sendiri untuk membentuk sebuah motivasi. Dari proses afektif, self efficacy akan mengatur emosi seseorang melalui beberapa cara, yaitu seseorang yang percaya akan mampu mengelola ancaman tidak akan mudah tertekan oleh diri mereka sendiri, tetapi sebaliknya jika seseorang memiliki self efficacy yang tinggi maka akan bisa menurunkan tingkat stres dan kecemasan. Dari proses seleksi akan memungkinkan seseorang untuk membentuk tindakan dan sebuah lingkungan yang sesuai akan membantu pembentukan diri dan pencapaian tujuan.

Dari hasil penelitian didapatkan ada korelasi positif antara self efficacy dengan quality of life. Seseorang yang memiliki self efficacy yang baik, akan mendorong seseorang untuk berperilaku yang positif dalam kehidupannya, sehingga dalam menjalani penyakit Diabetes mellitus yang dideritanya, penderita mampu mempertahankan dietnya, dan mampu melakukan pola hidup yang sehat sesuai dengan diet Diabetes mellitus.

\section{SIMPULAN}

Berdasarkan hasil penelitian, maka kesimpulan yang didapat adalah sebagai berikut: 
1) Nilai rata rata self efficacy pada responden di bawah nilai tengah untuk skor maksimal. (Skor 20-80).

2) Nilai rata rata quality of life berada di rentang cukup / nilai tengah untuk skor maksimal (Skor 20-100).

3) Terdapat hubungan yang positif antara self efficacy dan quality of life pasien Diabetes mellitus tipe 2. Dimana peningkatan self efficacy akan berpengaruh terhadap peningkatan quality of life.

\section{DAFTAR PUSTAKA}

ADA. (2012). Standards of Medical Care in Diabetes-2012. Journal of Diabetes Care, Vol.35, Supplement 1, January 2012, S11S63. Diperoleh dari http://care.diabetesjournals.org/ pada tanggal 18 April 2012.

ADA. (2012). Diagnosis and Classification of Diabetes Mellitus. Journal of Diabetes Care, Vol.35, Supplement 1, January 2012, S64S71. Diperoleh dari http://care.diabetesjournals.org/ pada tanggal 18 April 2012.

Almatsier, S. (2004). Penuntun Diet. Edisi ke-2. Instalasi Gizi Perjan RS Dr. Cipto Mangunkusumo dan Asosiasi Dietisien Indonesia. Jakarta: Gramedia Pustaka Utama.

nggina L.L., Hamzah Ali, Pandhit. (2010). Hubungan antara Dukungan Sosial Keluarga dengan Kepatuhan Pasien Diabetes Mellitus dalam Melaksanakan Program Diet di Poli Penyakit Dalam RSUD Cibabat Cimahi. Jurnal Penelitian Kesehatan Suara Forikes.

Bandura, A. (1997). Self Efficacy. Diperoleh dari http://www.des.emory.edu/mfp/Ba nEncy.html pada tanggal 3 Februari 2012.

Basuki, E. (2011). Penatalaksanaan Diabetes Mellitus Terpadu. Dalam
Soegondo et all (Ed.).Tehnik Penyuluhan Diabetes Mellitus. Edisi ke-2. Jakarta : Balai Penerbit FKUI.

Boedisantoso, A., Subekti, I.,(2011). Penatalaksanaan Diabetes Mellitus Terpadu. Dalam Soegondo et all (Ed.).Komplikasi Akut DiabetesMellitus. Edisi ke-2. Jakarta : Balai Penerbit FKUI.

Borrot N., Bush R., (2008). Measuring Quality of Life among those with type 2 diabetes in primary care. Diakses 15 Februari 2012, dari Healthy Communities Research Centre, The University of Queensland Web site : http://www.uq.edu.au/health/health ycomm/docs/QoL.pdf

Choi Yong Jun, Kim Ho Tae,. (2011). "The Relationship between Diabetes Mellitus and HealthRelated Quality of Life in Korean Adults : The Fourth Korea National Health and Nutrition Examination Survey (2007-2009). Diabetes \& Metabolism Journal. 35:587-594

Dharma Kelana K., (2011). Metodologi Penelitian Keperawatan : Panduan Melaksanakan dan Menerapkan Hasil Penelitian. Jakarta : Trans Info Media.

Diener,E.,Suh,E.M.,Lucas,R.,\&Smith,H.L. (1999). Subjective wellbeing:three decades of progress.Psychological Bulletin, 125 (2), $276-302$.

Gustaviani R,.(2006). Diagnosis dan Klasifikasi Diabetes mellitus. Dalam Sudoyo W.Aru, Setiyohadi Bambang, Alwi I, Simadibrata M, Setiati S (Ed.). Buku Ajar Ilmu Penyakit Dalam. Jilid III. Ed.IV (hal. 1857-1859). Jakarta : Pusat Penerbitan Departemen Ilmu Penyekit Dalam Fakultas Kedokteran Universitas Indonesia. 
Hariyono, (2010). Hubungan antara Self Care dan Lama Menderita dengan Kualitas Hidup penderita Diabetes Melltus di Poli Penyakit Dalam RSUD Jombang. Thesis FKP Unair. Tidak dipublikasikan. Surabaya : FKP Unair

Herijulianti, dkk. (2002). Pendidikan Kesehatan Gigi. Jakarta : EGC

Huang I-Chan, Hwang Chyng-Chuang, Lin Wender. (2008). DiabetesSpecific or Generic Measures for Health-Related Quality of Life?Evidence from Psychometric Validation of the D-39 and SF-36. Value in Health, 11(3).

Ilyas, Ermita.(2011). Olahraga bagi Diabetisi. Dalam Soegondo et all (Ed.).Diagnosis dan Klasifikasi Diabetes Mellitus Terkini. Edisi ke-2. Jakarta : Balai Penerbit FKUI.

Kuntoro. (2008). Metode Sampling dan

Penentuan Besar Sampel.

Surabaya : Pustaka Melati

Kuntoro. (2008). Metode Statistik. Surabaya : Pustaka Melati

Luszczynska A., Scholz U., Schwarzer R.. (2005). The General Self-Efficacy Scale : Multicultural Validation Studies. The Journal of Psychology, 139 (5), 439-457.

McDowell J, Courtney M, Edwards H, Shortridge-Baggett L. (2005) Validation of the Australian/English version of the Diabetes Management SelfEfficacy Scale. International Journal Nursing Practice, 11 : 177-84.

Muninjaya (2004). Manajemen Kesehatan. Jakarta : EGC

Nyunt SW, Howteerakul N, Suwannapong N,. (2010). Self-efficacy, Self-care Behaviors and Glycemic Control Among Type-2 Diabetes patients Attending Two Private Clinics in Yangon, Myanmar. Southeast
Asian J Trop Med Public Health. 41 (4) : $943-951$.

O'Connor,R.(2004). Measuring quality of life in health. Edinburgh : Churchill Livingstone.

Perkumpulan Endokrinologi Indonesia. (2011). Konsensus Pengelolaan dan Pencegahan Diabetes Melitus Tipe 2 di Indonesia, PB PERKENI. Jakarta

Polonsky, W.H. (2000). Understanding and assesing diabetes-spesific quality of life. Diabetes Spectrum, 13(1), $36-41$.

Rochmi W, (2009). Pengaruh Peer Support terhadap Diabetes Self Care Attitudes pada Penderita Diabetes mellitus tipe 2 di Desa Ngampel Kec.Papar Kediri. Skripsi FKP Unair. Tidak dipublikasikan. Surabaya : FKP Unair

Rondhianto, (2011). Pengaruh Diabetes Self management education Dalam Discharge Planning terhadap Self Efficacy dan Self Behaviour Pasien Diabetes Mellitus tipe 2. Thesis FKP Unair. Surabaya : FKP Unair.

Rose,M.,Fliege,H.,Hildebrandt,M.,Schirop ,T.,\&Klapp,B.F. (2002). The network of psychological variables in patients with diabetes and their importance for quality of life and metabolic control. Diabetes Care, 25 (1), $35-42$.

Shi, Q., S. K Ostwald, and S. Wang (2010). Improving glycaemic control selfefficacy and glycaemic control behaviour in Chinese patients with Type 2 diabetes mellitus: randomised controlled trial. Journal of Clinical Nursing. 398404. Diperoleh dari http://www.clinicalnursingjournal. org/. pada tanggal 12 Februari 2012.

Shortridge-Baggett, L.M. (2001). Self Efficacy : Measurement and 
Intervention in Nursing. Scholar Inguiry for Nursing Practice : An International Journal. 15 (3). 183188. Diperoleh dari http://scholaringuiryofnursingpracti cejournals.org/ akses pada tanggal 12 Februari 2012

Suyono, S. (2011). Penatalaksanaan Diabetes Mellitus Terpadu. Dalam Soegondo et all (Ed.).Patofisiologi Diabetes Mellitus. Edisi ke-2. Jakarta : Balai Penerbit FKUI.

Soegondo, S.(2011). Penatalaksanaan Diabetes Mellitus Terpadu. Dalam Soegondo et all (Ed.).Diagnosis dan Klasifikasi Diabetes Mellitus Terkini. Edisi ke-2. Jakarta : Balai Penerbit FKUI.

Sukarji, K.(2011). Penatalaksanaan Gizi pada Diabetes mellitus. Dalam Soegondo et all (Ed.).Diagnosis dan Klasifikasi Diabetes Mellitus Terkini. Edisi ke-2. Jakarta : Balai Penerbit FKUI.

The WHOQoL project. Quality of Life, retrieved November 28th from http://.acpmh.unimelb.edu.

Tjokroprawiro, A., et all (2008). Diabetes Mellitus. Dalam Pedoman Diagnosis dan Terapi Bag/SMF Ilmu Penyakit Dalam. Ed. III (8590). Surabaya : Rumah Sakit Umum Dokter Soetomo.

Tjokroprawiro, A., (2011). Hidup Sehat dan Bahagia Bersama Diabetes : Panduan Lengkap Pola Makan untuk Penderita Diabetes. Ed.revisi ke-3. Jakarta : PT.Gramedia Pustaka Utama anggota IKAPI.

Ventegodt, S.(2003). Quality of Life Theory. The IqoL Theory : An Integrative Theory of The Global of Life Concept, Ben Gurion University, Denmark.

Vivienne Wu S., Courtney M., Edwards H., McDowell J., et all. (2008). Development and Validation of the
Chinese version of the Diabetes Management Sefl-Efficacy Scale. International Journal of Nursing Studies, 45, 534-542.

Wardhani Putri Wisnu. (2009). Hubungan Nilai Budaya Uncertainty Avoidance (UA) dengan Tingkah Laku Inovatif. Skripsi Fpsi Universitas Indonesia. Jakarta : Universitas Indonesia.

Waspadji, S. (2009). Pedoman Diet Diabetes Mellitus. Edisi ke-2. Jakarta : Balai Penerbit FKUI

Waspadji, S.(2011). Penatalaksanaan Diabetes Mellitus Terpadu. Dalam Soegondo et all (Ed.).Diabetes Mellitus : Mekanisme Dasar dan Pengelolaannya yang Rasional. Edisi ke-2. Jakarta : Balai Penerbit FKUI.

WHOQoL Group, (2009). WHOQoL BREF, Introduction, Administration, scoring, and generic version of the assessment, field trial version. Retrieved November 28th, 2002 from http://www.popcouncil.org/horizon tal/.

World Health Organization, (2003). Health Topics : Diabetes. Diakses 1 Maret 2012, dari http://www.who.int/topics/diabetes mellitus

World Health Organization, (2012). Health Topics : Diabetes. Diakses 26 Pebruari 2012, dari http://www.who.int/topics/diabetes _mellitus

Wu, S. F. (2007). Effectiveness of Self Management for Persons with type 2 diabetes following the Implementation of a Self Efficacy enhancing Intervention Program in Taiwan. Quensland University of Technology; Schooll of Nursing. Diperoleh dari http://eprints.qut.edu.au/ pada tanggal 10 Februari 20. 